\section{ORIG IN A L ARTICLE}

\title{
Pharmacological mechanisms involved in the antinociceptive effects of dexmedetomidine in mice
}

\author{
Rafael A. S. Rangel ${ }^{\mathrm{a}}$, Bruno G. Marinhob ${ }^{\mathrm{b}}$, Patrícia D. Fernandes ${ }^{\mathrm{b}}$, \\ Roberto S. de Moura ${ }^{\mathrm{a}}$, Marcos A. Lessa ${ }^{\mathrm{c} *}$ \\ ${ }^{a}$ Department of Pharmacology and Psychobiology, State University of Rio de Janeiro, Rio de Janeiro, Brazil \\ ${ }^{\mathrm{b}}$ Drugs Developmental Program, Institute of Biomedical Science, Federal University of Rio de Janeiro, Rio de Janeiro, \\ Brazil \\ ${ }^{\mathrm{c}}$ Laboratory of Cardiovascular Investigation, Oswaldo Cruz Institute, FIOCRUZ, Rio de Janeiro, Brazil
}

\section{Keywords \\ antinociception, dexmedetomidine, nitric oxide, pain}

Received 9 May 2012; revised 12 July 2012 ; accepted 19 July 2012

*Correspondence and reprints: malessa@ioc.fiocruz.br

\begin{abstract}
Dexmedetomidine (DEX) is a $\alpha_{2}$-adrenoceptor $\left(\alpha_{2}\right.$-AR) agonist used as an anesthetic adjuvant and as sedative in critical care settings. Typically, $\alpha_{2}$-AR agonists release nitric oxide (NO) and subsequently activate NO-GMPc pathway and have been implicated with antinociception. In this study, we investigate the pharmacological mechanisms involved in the antinociceptive effects of DEX, using an acetic acid-induced writhing assay in mice. Saline or DEX $(1,2$, 5, or $10 \mu \mathrm{g} / \mathrm{kg})$ was intravenously injected $5 \mathrm{~min}$ before ip administration of acetic acid and the resulting abdominal constrictions were then counted for $10 \mathrm{~min}$. To investigate the possible mechanisms related to antinociceptive effect of DEX $(10 \mu \mathrm{g} / \mathrm{kg})$, the animals were also pretreated with one of the following drugs: 7-nitroindazole (7-NI; $30 \mathrm{mg} / \mathrm{kg} \mathrm{ip}) ; 1 \mathrm{H}-[1,2,4]$ oxadiazole [4,3-a] quinoxaline-1-one (ODQ; $2.5 \mathrm{mg} / \mathrm{kg}$, ip); yohimbine (YOH; $1 \mathrm{mg} / \mathrm{kg}$, ip); atropine (ATRO; $2 \mathrm{mg} / \mathrm{kg}$, ip); glibenclamide (GLIB; $1 \mathrm{mg} / \mathrm{kg}$, i.p.) and naloxone (NAL; $0.2 \mathrm{mg} / \mathrm{kg}$, ip). A rotarod and open-field performance test were performed with DEX at $10 \mu \mathrm{g} / \mathrm{kg}$ dose. DEX demonstrated its potent antinociceptive effect in a dose-dependent manner. The pretreatment with 7-NI, ODQ, GLIB, ATRO, and YOH significantly reduced the antinociceptive affects of DEX. However, NAL showed no effecting DEX-induced antinociception. The rotarod and open-field tests confirmed there is no detectable sedation or even significant motor impairment with DEX at $10 \mu \mathrm{g} / \mathrm{kg}$ dose. Our results suggest that the $\alpha_{2}$-AR and NO-GMPc pathways play important roles in the systemic antinociceptive effect of DEX in a murine model of inflammatory pain. Furthermore, the antinociceptive effect exerted by DEX appears to be dependent on $\mathrm{K}_{\mathrm{ATP}}$ channels, independent of opioid receptor activity.
\end{abstract}

\section{INTRODUCTION}

Dexmedetomidine (DEX) is a highly selective $\alpha_{2}$-adrenoceptor $\left(\alpha_{2}-\mathrm{AR}\right)$ agonist that has been largely used for anxiolysis, sedation, and analgesia in mechanically ventilated patients in critical care settings. One therapeutic advantage of DEX is a sedative effect with minimal ventilatory impairment. DEX also decreases surgical sympathoadrenal responses and reduces the intraoperative opioid analgesic requirement [1]. The antinociceptive actions of $\alpha_{2}$-AR agonists have been demonstrated in experimental and clinical studies [2, 3]. It is well known that $\alpha_{2}$-AR activation of both spinal and supraspinal nuclei is involved in the antinociceptive action of $\alpha_{2}$-AR agonists. Activation of $\alpha_{2}$-ARs reduces the release of pronociceptive neurotransmitters, such as substance P and glutamate, from primary afferent terminals [4] and hyperpolarizes 
spinal interneurons via G-protein-mediated activation of $\mathrm{K}^{+}$channels [5].

However, the mechanisms related to the antinociceptive effects of $\alpha_{2}$-AR agonists are not entirely understood. Most of the data concerning the antinociceptive properties of $\alpha_{2}$-AR agonists have been obtained from studies using clonidine as the $\alpha_{2}$-AR agonist prototype. In this context, clonidine induces the release of nitric oxide (NO) [6], an important modulator of neuronal activity that plays a significant role in the peripheral and central mechanisms of antinociception [7, 8]. Moreover, clonidine-dependent NO release has been described even for intracerebroventricularly injected $\alpha_{2}$-AR agonists in mice submitted to the tail-flick model of acute pain [9]. The antinociceptive, sedative [10], and antihypertensive [11] actions of clonidine probably share common NO-GMPc pathways. These therapeutic effects are mediated at the brain stem, mainly at the locus coeruleus, a key adrenergic center that sends neural projections to the spinal cord as part of the descending adrenergic analgesic system $[12,13]$.

The involvement of the muscarinic system in antinociception at the spinal cord level is well recognized [12, 14-17]. In this context, it has already been demonstrated that spinal muscarinic receptors mediate the analgesic action of $\alpha_{2}$-AR agonists intrathecally administrated [18], suggesting a definitive link between noradrenergic and cholinergic pathways in spinal antinociception. Inhibitory neurons are responsible for these antinociceptive effects through the release of analgesic neurotransmitters, such as endogenous opioid peptides and adenosine. Pertovaara [19] has determined that norepinephrine exerts pain relief by acting on $\alpha_{2}$-ARs (presynaptic and postsynaptic inhibition) and by $\alpha_{1}$-AR activation of inhibitory interneurons. Moreover, the effects of $\alpha_{2}$-ARs on the axon terminals of excitatory neurons in the spinal dorsal horn may be involved in the spinal control of pain [19].

Different analgesic drugs, including $\alpha_{2}$-AR agonists $[20,21]$, elicit an independent and complementary antinociceptive mechanism through the opening of ATP-dependent $\mathrm{K}^{+}$channels $\left(\mathrm{K}_{\mathrm{ATP}}\right)$. In addition to the opening of $\mathrm{K}_{\mathrm{ATP}}$, analgesic drugs also activate NO, GMPc, and protein kinases in GMPc-dependent pathways. The pharmacological opening of $\mathrm{K}_{\mathrm{ATP}}$ alone is not sufficient for antinociception but may enhance the antinociception achieved by other agents, such as morphine and DEX [22].

Despite the recent widespread utilization of DEX in critical care and anesthesia practice, the involvement of the NO-GMP pathway in the antinociceptive effects of DEX is not completely understood. Thus, our objective was to investigate the underlying mechanism of the DEX-induced antinociceptive effect in a classical mouse model of inflammatory pain.

\section{MATERIAL AND METHODS}

\section{Animals}

Male mice $(20-30 \mathrm{~g})$ were housed in the animal care facility at $23 \pm 1{ }^{\circ} \mathrm{C}$ and maintained on a 12-h light/ dark cycle. The animals were allowed free access to food and water until $2 \mathrm{~h}$ before the experiments. The animal handling and experimental procedures were approved by the Ethical Committee for Use of Experimental Animals of the State University of Rio de Janeiro (license number 00356/05) and were carried out in accordance with the European Communities Council Directive of 24 November 1986 (86/609/EEC). The animals were acclimatized to the laboratory for at least $2 \mathrm{~h}$ before the testing. The animals were used only during the protocol and were killed immediately after the algesimeter test. The control animals were evaluated concurrently and interspersed with the drugtreated animals, which prevented having all the control animal be from one group evaluated at one time during the course of the investigation. The number of animals was kept at the minimum that was compatible with consistent drug treatments and the assessor was blinded to treatment allocation at the time of behavioral assessments.

\section{Measurement of antinociceptive activity}

The antinociceptive activity of DEX was assessed by the acetic acid-induced writhing test, a classical model of chemical/inflammatory pain largely used for testing analgesic drugs in the mouse [23]. The mice were injected, via intraperitoneal (ip), with an acetic acid solution $(10 \mathrm{~mL} / \mathrm{kg}, \quad 0,8 \% \mathrm{v} / \mathrm{v})$ and placed in a $40 \times 30 \times 25 \mathrm{~cm}$ Plexiglas box that was maintained in a quiet illuminated room. The resulting abdominal constrictions (writhes) were then counted for $10 \mathrm{~min}$, starting at $5 \mathrm{~min}$ after the administration of the acetic acid solution. One writhe was defined as a contraction of the abdominal musculature followed by an extension of the forelimbs and elongation of the animal's body. Antinociceptive activity was defined as the significant reduction in the number of writhes (NOW) compared with the control group. Saline or DEX $(1,2,5$, and $10 \mu \mathrm{g} / \mathrm{kg}$ ) was intravenously injected in the dorsal vein 
of the tail $5 \mathrm{~min}$ before the ip administration of the acetic acid solution. In subsequent experiments, the dose of DEX with best antinociceptive response $(10 \mu \mathrm{g} /$ $\mathrm{kg}$ ) was used for rotarod and open-field performance tests and for the pharmacological investigation of the antinociceptive effect of DEX.

\section{Rotarod performance test}

The rotarod test is an established method for evaluating motor impairment and ataxia [24]. The day before the test, the animals were twice trained to maintain equilibrium for $5 \mathrm{~min}$ on a roller apparatus ('Rotarod for mice', Insight, Brazil). The speed selector was set to $10 \mathrm{rev} / \mathrm{min}$. The animals that fell from the roller twice during the $5 \mathrm{~min}$ of testing were discarded. Twentyfour hours later, the mice were intravenously treated with DEX $(10 \mu \mathrm{g} / \mathrm{kg})$, diazepam (DZP $-1 \mathrm{mg} / \mathrm{kg})$, or vehicle, and then placed again on the roller for $5 \mathrm{~min}$. A neurological deficit was defined as an animal being unable to remain on the roller for the test period and was measured by the number of times that the animal fell off the roller.

\section{Assessment of spontaneous activity - open-field test}

The procedure was similar to the method described by Barros et al. [25]. The mice received DEX (10 $\mu \mathrm{g} / \mathrm{kg})$, DZP (1 mg/kg), or vehicle by intravenous injection and were immediately placed individually in an observation chamber with a floor divided into 50 squares $(5 \times 5 \mathrm{~cm})$. The total number of squares on which a mouse walked during 5 min was counted at intervals of 20 min varying from 20 to 120 min after the drug administration. The following formula based on the trapezoid rule was used to calculate the AUC: AUC $=20 \times[(\min 20)+(\min 40)+\ldots+(\min 120) / 2]$.

\section{Pharmacological mechanisms involved in the antinociceptive effect of dexmedetomidine}

To investigate the possible mechanisms related to antinociceptive effect of DEX, the animals were also pretreated with one of the following drugs: 7-nitroindazole (7-NI; $30 \mathrm{mg} / \mathrm{kg}$ ip), a selective inhibitor of neuronal nitric oxide synthase; $1 \mathrm{H}-[1,2,4]$ oxadiazole [4,3-a] quinoxaline-1-one (ODQ; $2.5 \mathrm{mg} / \mathrm{kg}$, ip), a highly selective, irreversible heme-site inhibitor of soluble guanylyl cyclase; yohimbine $(\mathrm{YOH} ; 1 \mathrm{mg} / \mathrm{kg}$, ip), a presynaptic $\alpha_{2}$-AR blocking agent; atropine (ATRO; $2 \mathrm{mg} / \mathrm{kg}$, ip), a competitive muscarinic acetylcholine receptor antagonist; glibenclamide (GLIB; 1 $\mathrm{mg} / \mathrm{kg}$, i.p.), an inhibitor of ATP-sensitive potassium channels; and naloxone (NAL; $0.2 \mathrm{mg} / \mathrm{kg}$, ip), a competitive opioid receptor antagonist. In separate groups, we assessed the possible effects of the vehicles (saline and DMSO at $7.5,27.8$, or 5 plus $5 \%$ ethylic alcohol in saline, depending on the antagonist) when injected im 25 min before the DEX treatment.

\section{Statistical analysis}

The results are expressed as the mean \pm SEM for each group of six animals, and comparisons between the different groups were made with one-way analysis of variance (ANOVA). If a significant difference was detected by ANOVA, the Bonferroni test was used to identify the statistically significant differences. Differences with a $P<0.05$ were considered significant. All calculations were made by computer-assisted analyses with a commercially available statistical package (Graphpad Instat 5.0; GraphPad Software Inc., La Jolla, CA, USA).

\section{Drugs}

The ATRO, NAL, and $\mathrm{YOH}$ were diluted in saline. The 7 -NI and ODQ were diluted in 7.5\% DMSO in saline and $27.8 \%$ DMSO in saline, respectively. The glibenclamide(GLIB) was diluted in 5\% ethylic alcohol and 5\% DMSO saline solution. The DEX hydrochloride was purchased from Abbott Laboratories, Rio de Janeiro, Brazil. The 7-NI, NAL, YOH, and GLIB were purchased from Sigma, St. Louis, MO, USA. The ODQ was purchased from Calbiochem-Novabiochem, Canada. The ATRO and DZP were purchased from União Química Farmacêutica Nacional Rio de Janeiro, RJ, Brazil.

\section{RESULTS}

\section{Antinociceptive effect of dexmedetomidine}

When intravenously administered in the tail vein, DEX induced a significant and dose-dependent antinociceptive effect against acetic acid-induced inflammatory peritoneal pain; doses of $1,2,5$, and $10 \mu \mathrm{g} / \mathrm{kg}$ of DEX produced antinociceptive effect characterized as a significant reduction in the NOW in the writhing test $(34 \pm 1, \quad 34 \pm 2, \quad 22 \pm 1, \quad$ and $6 \pm 1$, respectively. $P<0.05-$ Figure 1). The dose that elicited the greatest antinociceptive effect was $10 \mu \mathrm{g} / \mathrm{kg}$, and this dose was used in the pharmacological protocol to study the possible mechanisms of the antinociceptive effect of DEX. 


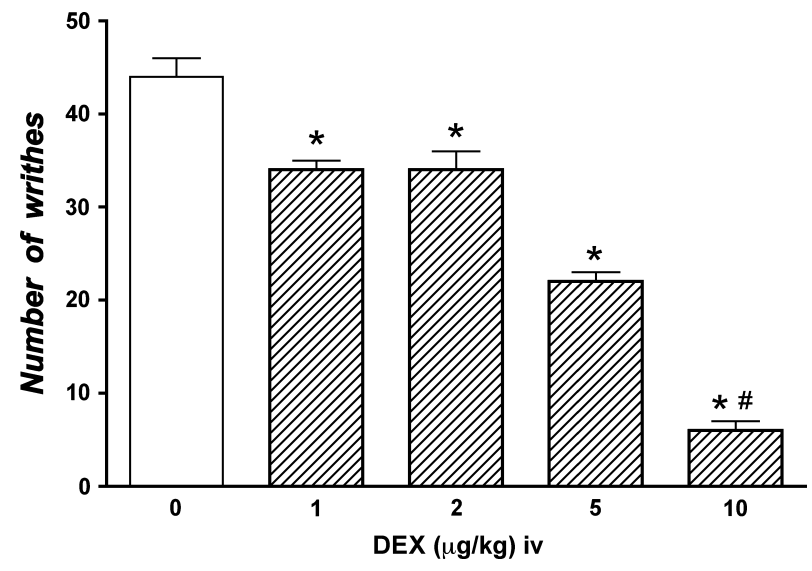

Figure 1 The antinociceptive effect of dexmedetomidine (DEX) assessed by the writhing test in mice. The results are presented as mean \pm SEM; $n=6$ animals for each group, one-way ANOVA followed Bonferroni test. ${ }^{*} P<0.05$ vs. saline $\# P<0.05$ vs. DEX $0,1,2$, and $5 \mu \mathrm{g} / \mathrm{kg}$.

\section{Rotarod performance test}

In the Rotarod performance test, DEX $(10 \mu \mathrm{g} / \mathrm{kg}$, iv $)$ presented a similar result when compared with the vehicle group $(0.8 \pm 0.4$ and $0.7 \pm 0.3$, respectively). The positive control with DZP $(1 \mathrm{mg} / \mathrm{kg}$, iv) produced a significant increase in the number of falls compared with the vehicle and DEX groups $(6.5 \pm 1.1, P<0.05$ - Figure 2).

\section{Assessment of spontaneous activity - open-field test}

In the open-field test, the curves representing DEX $(10 \mu \mathrm{g} / \mathrm{kg}$, iv) and vehicle groups overlapped, while the positive control with DZP $(1 \mathrm{mg} / \mathrm{kg}, \quad$ iv $)$

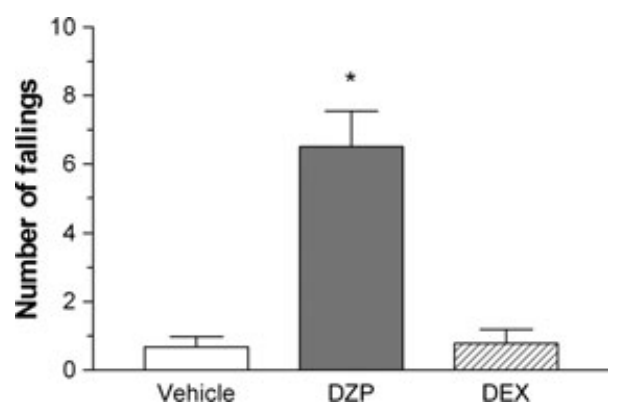

Figure 2 The effect of dexmedetomidine (DEX - $10 \mu \mathrm{g} / \mathrm{kg}$ ), diazepam (DZP - $1 \mathrm{mg} / \mathrm{kg}$ ), and the vehicle on the mice in the Rotarod test. The results are presented as mean \pm SEM; $n=6$ animals for each group, one-way ANova followed Bonferroni test. $* P<0.05$ vs. vehicle and DEX. significantly reduced the number of walked squares throughout the experiment compared with the vehicle group (Figure 3a).

Figure $3 b$ shows that the area under the curve (AUC) of the DEX graph was similar to that of the vehicle $(5125 \pm 621$ and $4964 \pm 622$ squares in $120 \mathrm{~min}$, respectively), while the positive control with DZP significantly reduced the AUC of the number of walked squares $(3193 \pm 425, P<0.05)$ throughout the experiment compared with the vehicle group.

\section{Role of NO synthase and guanylyl cyclase on the antinociceptive effect of dexmedetomidine}

Inhibiting NO synthase by 7-NI did not change the writhing tests when compared with the vehicle $(36 \pm 1$ and $36 \pm 2$, respectively - Figure $4 a)$. However, the 7-NI pretreatment significantly reduced the
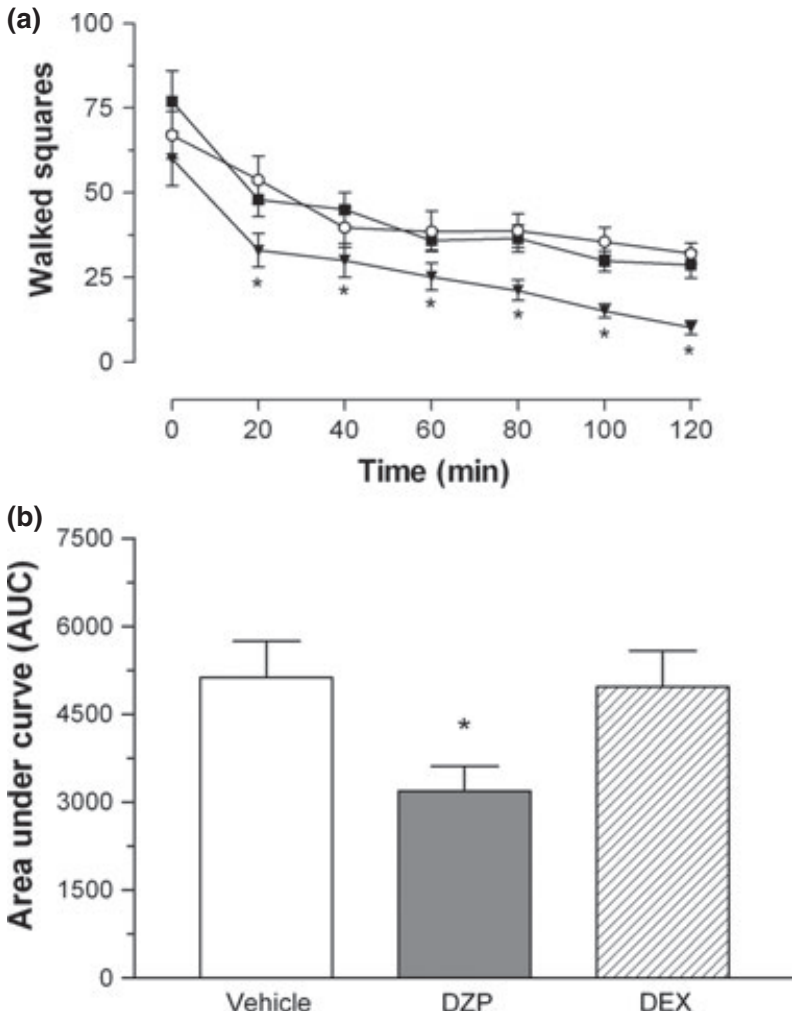

Figure 3 The effect of dexmedetomidine (DEX), diazepam (DZP), and the vehicle on the mice in the open-field test. The mice received DEX (匹, $10 \mu \mathrm{g} / \mathrm{kg})$, DZP $(\boldsymbol{\nabla}, 1 \mathrm{mg} / \mathrm{kg})$, or the vehicle (o). In (a), the graph represents the number of walked squares against time. In (b), the graph represents the area under the curve (AUC) calculated for each time-effect curve. The results are presented as mean \pm SEM; $n=6$ animals for each group, oneway ANova followed Bonferroni test. $* P<0.05$ vs. vehicle. 

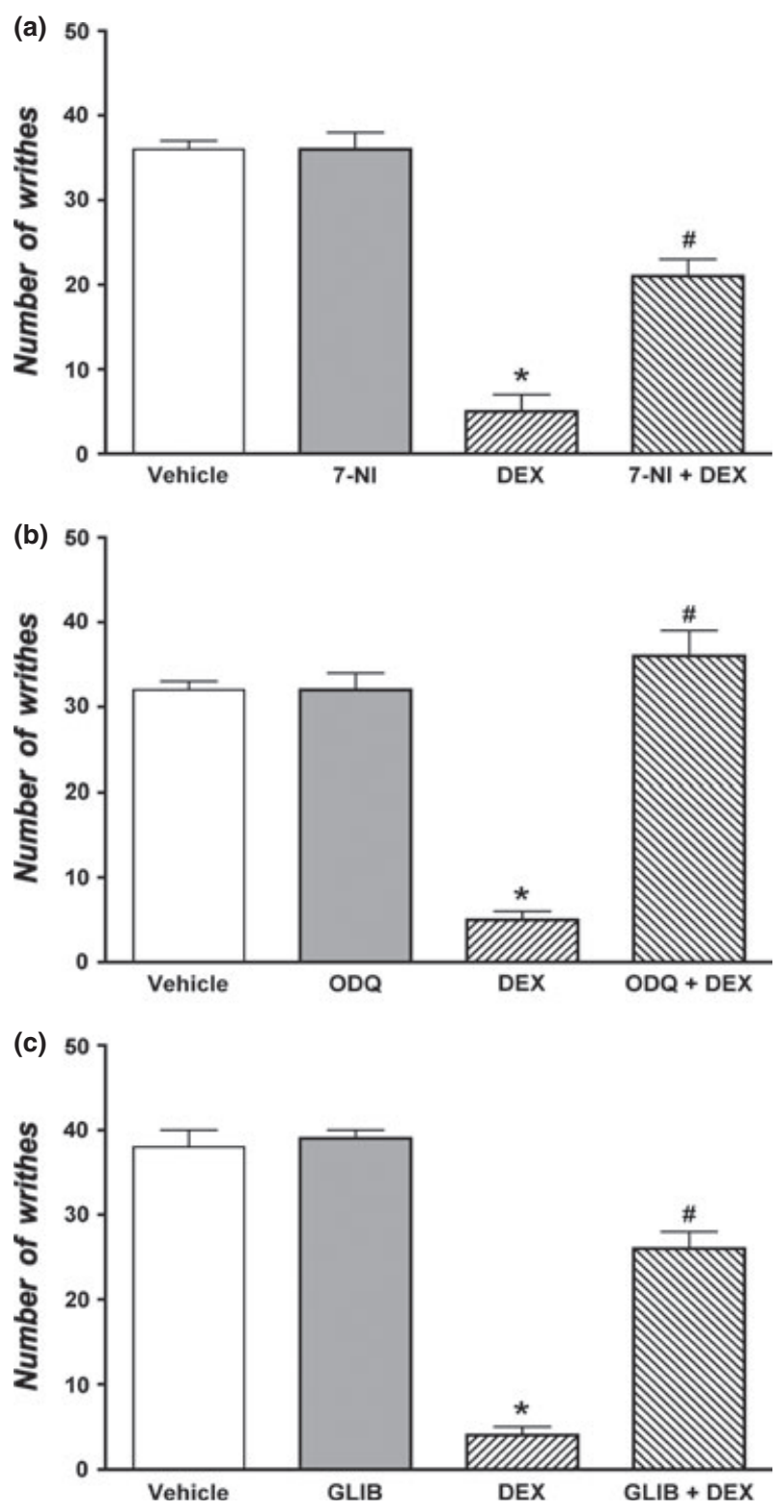

Figure 4 The effect of pretreatment with 7-NI (a), ODQ (b), and glibenclamide (c) on dexmedetomidine (DEX)-induced antinociception in mice, as assessed by the writhing test. The results are presented as mean \pm SEM; $n=6$ animals for each group, one-way ANova followed Bonferroni test. $* P<0.05$ vs. vehicle ${ }^{\#} P<0.05$ vs. DEX.

antinociceptive effect of DEX; the NOW increased from $5 \pm 2$ in the DEX group to $21 \pm 2$ in the 7 -NI + DEX group $(P<0.05-$ Figure $4 a)$. Soluble guanylyl cyclase was inhibited by administering $2.5 \mathrm{mg} / \mathrm{kg}$ of ODQ, which did not change the writhing test when compared with the vehicle $(32 \pm 1$ and $32 \pm 2$, respectively - Figure 4b). By contrast, the ODQ pretreatment significantly reduced the antinociceptive effect of DEX; the NOW increased from $5 \pm 1$ in the DEX group to $36 \pm 3$ in the ODQ + DEX group $(P<0.05-$ Figure $4 b)$.

\section{Effects of glibenclamide on the dexmedetomidine-induced antinociception}

The $\mathrm{K}_{\mathrm{ATP}}$ channel blockade by GLIB did not change the results of the writhing test when compared with the vehicle ( $39 \pm 1$ and $38 \pm 2$, respectively - Figure 4c). However, the GLIB pretreatment significantly reduced the antinociceptive effect of DEX; the NOW increased from $4 \pm 1$ in the DEX group to $26 \pm 2$ in the GLIB + DEX group (Figure 4c).

\section{The effects of atropine on dexmedetomidine- induced antinociception}

When administered alone, ATRO did not exhibit any antinociceptive effects in the writhing test when compared with the vehicle (39 \pm 1 and $41 \pm 3$, respectively - Figure 5a). Conversely, the ATRO pretreatment significantly reduced the DEX-induced antinociception increasing the NOW from $5 \pm 1$ in the DEX group to $30 \pm 2$ in the ATRO + DEX group $(P<0.05-$ Figure 5a).

\section{Effects of yohimbine on the dexmedetomidine- induced antinociception}

YOH did not exhibit any antinociceptive effects in the writhing test (Figure $5 b$ ). However, the $\mathrm{YOH}$ pretreatment significantly reduced the DEX-induced antinociception; the NOW increased from $6 \pm 2$ in the DEX group to $39 \pm 2$ in the YOH + DEX group $(P<0.05-$ Figure $5 b)$.

\section{Effects of naloxone on the dexmedetomidine- induced antinociception}

The opioid receptor antagonism did not exhibit any antinociceptive effects in the writhing test. NAL group presented the same NOW when compared with the saline group ( $43 \pm 3$ and $43 \pm 2$, respectively) and the pretreatment with NAL (NAL + DEX) group did not reduce the antinociceptive effect of DEX $(4 \pm 1$ and $5 \pm 1$, respectively - Figure $5 c$ ).

\section{DISCUSSION}

Our results indicate that the systemic administration of DEX dose dependently reduces the pain-induced behavior triggered by injecting intraperitoneal acetic acid into mice. We also demonstrated that the antinociceptive 

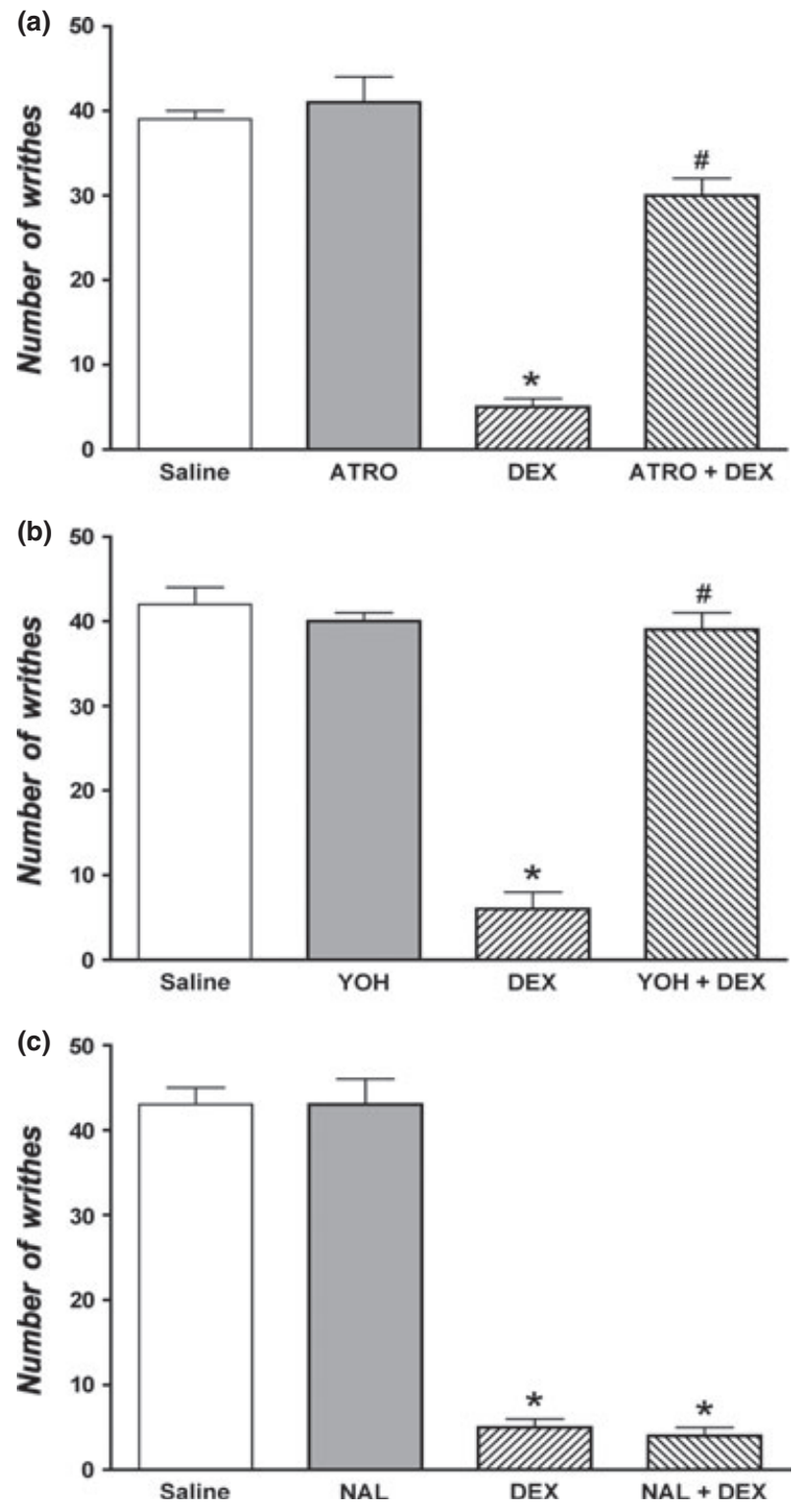

Figure 5 The effect of pretreatment with atropine (a), yohimbine (b), and naloxone (c) on dexmedetomidine (DEX)-induced antinociception in mice, as assessed by the writhing test. The results are presented as mean \pm SEM; $n=6$ animals for each group, one-way anova followed Bonferroni test. $* P<0.05$ vs. vehicle ${ }^{\#} P<0.05$ vs. DEX.

effects of DEX are related to the NO activity, the opening of $\mathrm{K}_{\text {АTP }}$ channels, and muscarinic activation. By contrast, pretreatment with NAL did not change the antinociceptive action of DEX, suggesting that opioid receptors are not involved in DEX-induced antinociception.

The antinociceptive effect of DEX has been studied over the last 15 years, and the results consistently demonstrate that DEX induces significant antinociception in different models, such as those for cutaneous [26-28] and visceral [29, 30] pain. In this context, DEX is able to reduce spontaneous pain-related behaviors (muscle contractions, abdominal licking, and stretching) in visceral pain, such as capsaicin-induced intracolonic pain [29], and in acetic acid-induced intraperitoneal pain [30]. Consistent with these previous studies, our results indicate that systemic treatment with DEX effectively reduces the number of writhes in mice.

When studying $\alpha_{2}$-AR agonists, it is important to determine whether the reduction in the NOW after iv DEX treatment is an antinociceptive or a sedative effect. Sedation is the main side effect of most $\alpha_{2}$-AR agonists, and DEX was developed for its sedative effects. In our study, however, the intravenous administration of $10 \mu \mathrm{g} / \mathrm{kg}$ of DEX induced significant antinociceptive effects without any change in motor coordination, as evaluated by the Rotarod test, and spontaneous motor activity, as assessed by the open-field test. Moreover, pharmacological studies in rats using different routes of administration, such as intrathecal [31], intraperitoneal [28], or iv [32], strongly suggest that the dose of DEX used in our study has a significant antinociceptive effect without producing sedation or motor impairment.

In our study, the involvement of the NO in DEXinduced antinociception was demonstrated by the inhibitory effect of 7-NI, an inhibitor of neuronal NO synthase, and further strengthened by ODQ, significantly reducing the antinociceptive effect of DEX. Although the NO-cGMP pathway is an effector system that is classically coupled to the $\alpha_{2}$-AR, the role of cGMP in the action of $\alpha_{2}$-AR agonists is not completely understood. The decrease of cGMP elicited by $\alpha_{2}$-AR agonists in diverse cerebral areas is related to many therapeutic effects, such as the sympatholytic, sedativehypnotic, anxiolytic, analgesic, and anesthetic-sparing actions of these drugs [33].

$\mathrm{K}_{\mathrm{ATP}}$ channels are widely distributed in the central and peripheral nervous system [34] and are involved in many different neuronal activities, such as neuroprotection, control of neurotransmitter release, and regulation of membrane excitability [34-36]. Interestingly, opening of $\mathrm{K}_{\mathrm{ATP}}$ channels and the consequent cellular hyperpolarization are involved in the antinociceptive effects of drugs with dissimilar mechanisms of action, such as ketorolac [20], baclofen, and $\alpha_{2}$-AR agonists [21]. In our study, GLIB significantly 
attenuated the antinociceptive effect of DEX, confirming the important role of antinociceptive $\mathrm{K}_{\mathrm{ATP}}$ channels in the analgesic effects of $\alpha_{2}$-AR agonists. In our experimental protocol, we reduced the $\mathrm{K}_{\mathrm{ATP}}$ current by the systemic administration of GLIB. It is not possible to identify the exact location of the $\mathrm{K}_{\mathrm{ATP}}$ channel blockade, but there are some candidates at the spinal, brain, and even peripheral levels [37]. The loss of $K_{\text {ATP }}$ current contributes to neuropathic pain, possibly through varied mechanisms that include increased membrane excitability, amplification of excitatory neurotransmitter release, regulation of neuronal excitability [34-36, 38], and (possibly) increased susceptibility to cell death.

A variety of drugs that modulate medullar acetylcholine (Ach) concentration and metabolism interact with the antinociceptive properties of $\alpha_{2}$-AR agonists. Several studies have clearly demonstrated that cholinergic pathways are implicated in antinociception at the spinal level $[15,16,39,40]$. In our study, we also demonstrated that systemic ATRO attenuates the antinociceptive effect of DEX. It is noteworthy that ATROinduced cholinergic receptor blockade is a central effect that involves medullar and supra-medullar centers related to antinociception [41]. Moreover, cholinergic pain modulation may also involve first-order neurons (sensory neurons responsible for delivering sensory information to the central nervous system) via muscarinic acetylcholine M2 receptors. In this context, Dussor et al. [42] have demonstrated that activating peripheral M2 receptors produces antinociception in vivo and inhibits antinociceptive activity in vitro. In cultured rat dorsal root ganglia cells, DEX also inhibits muscarinic type 3 receptors and muscarine-induced intracellular $\mathrm{Ca}^{2+}$ elevation [43].

The effect of DEX on nonadrenergic imidazoline-preferring binding sites is another possibility to consider. It is well known that DEX has an imidazoline-like structure and some degree of imidazoline affinity [12]. In our study, we used $\mathrm{YOH}$ to ensure that the blockade of the antinociceptive effect of DEX was not related to activation of the imidazoline-preferring binding sites that exist in the brain and peripheral tissue. We successfully abolished the antinociceptive effect of DEX using $\mathrm{YOH}$, a classical $\alpha_{2}$-AR antagonist without the imidazoline ring. Similar results in various previous studies have demonstrated that $\alpha_{2}$-AR antagonist block the antinociceptive effects of clonidine [8] and DEX [44]. It is interesting to note that $\mathrm{YOH}$ pretreatment is able to block the effects of DEX administered by the intravenous [32], intrathecal, or intraperitoneal [44] routes.

The spinal anatomic distribution of all three $\alpha_{2}$-AR subtypes $\left(\alpha_{2 \mathrm{~A}}, \alpha_{2 \mathrm{~B}}\right.$, and $\left.\alpha_{2 \mathrm{C}}\right)$ had been described using in situ hybridization and links the anatomic adrenergic areas along with cervical, thoracic, and lumbar spinal to the antinociception process [45]. All three $\alpha_{2}$-AR subtypes act as presynaptic inhibitory feedback receptors to control the release of catecholamines from neurons. Alpha $2 \mathrm{~A}-\mathrm{AR}$ subtype activation is required for the hypnotic, analgesic, seizure-modulating, and central anti-hyperalgesia effects of $\alpha_{2}$-AR agonists [29, 46]. Alpha $_{2 \mathrm{~B}}-\mathrm{AR}$ subtype is an essential component of descending noradrenergic neurons in the spinal cord and mediates the analgesic, but not the sedative effect of nitrous oxide [47]. Alpha $2 \mathrm{C}^{-\mathrm{AR}}$ activation in the CNS is related to memory and behavioral functions that significantly interfere with the antinociception process $[48,49]$.

To verify the possible role of opioid receptors in the antinociceptive effects of DEX in our model of inflammatory pain, the rats were pretreated with NAL, a classical nonselective opioid receptor antagonist. NAL did not interfere with the antinociceptive effect of DEX, suggesting that opioid receptors are not involved in this effect, at least under our experimental conditions. The absence of interactions between DEX and the opioid system has also been demonstrated in previous studies performed in dogs [50] and neonatal rats [51]. Moreover, there is some pharmacological evidence showing that NAL has no effect on the antinociceptive properties of clonidine either [8]. By contrast, others' studies have found evidence that the opioid system may contribute to DEX-induced antinociception [52, 53]. In this context, Ulger et al. [32] have recently demonstrated that the antinociceptive effects of IV DEX were significantly reduced by NAL. In fact, intravenous opioid administration induces the spinal release of norepinephrine and acetylcholine, thus activating the descending spinal noradrenergic and cholinergic pathways involved in analgesia [54]. Moreover, opioid receptors and the $\alpha_{2}$-AR belong to the superfamily of G-protein-coupled receptors and share certain pathways involved in antinociception, such as adenylyl cyclase inhibition, rectifying $\mathrm{K}^{+}$channel opening, and decreased conductance in voltage-gated $\mathrm{Ca}^{2+}$ channels. However, our results suggest that the activation of opioid receptors is not involved in the antinociceptive effect of systemic DEX in our experimental model of acetic acid-induced inflammatory pain. The controversy 
involving the opioid system and the antinociceptive effect of DEX may be related to the use of completely different experimental models of nociception in different animal species.

It is important to remember that the cellular effects of DEX are not limited to its interactions with $\alpha_{2}$-AR. Recent evidence has suggested that DEX-induced changes in neuronal activity may involve ion channels, principally those of $\mathrm{K}^{+}[55,56], \mathrm{Ca}^{2+}[57]$, and $\mathrm{Na}^{+}$ [55]. DEX causes phosphorylation of $\mathrm{ERK}_{1}$ and $\mathrm{ERK}_{2}$ $[58,59]$ in cultured mouse astrocytes and increases the expression of brain-derived neurotrophic factor and epidermal growth factor [58], both of which are involved in neuroprotection. Moreover, DEX suppresses the expression of different markers of inflammation such as cyclo-oxygenase- 2 , TNF- $\alpha$, IL- $1 \beta$, IL- 6 , inducible nitric oxide synthase, and interferon gamma [60]. DEX also has preconditioning and postconditioning effects against ischemic injury in neuronal cells in vitro [61].

In conclusion, the results of our study showed that the $\alpha_{2}$-AR and NO pathways play important roles in the systemic antinociceptive effect of DEX in mice. Furthermore, we believe that the antinociceptive effect exerted by DEX is dependent on $\mathrm{K}_{\text {ATP }}$ channels and independent of opioid receptor activity, at least in our experimental model of pain-induced behavior triggered by intraperitoneal acetic acid injection in mice.

\section{CONFLICT OF INTEREST}

The authors declare no conflict of interest.

\section{FINANCIAL SUPPORT}

CNPq, Fiocruz, and FAPERJ.

\section{REFERENCES}

1 White P.F. The changing role of non-opioid analgesic techniques in the management of postoperative pain. Anesth. Analg. (2005) 101 S5-S22.

2 Maze M., Tranquilli W. Alpha-2 adrenoceptor agonists: defining the role in clinical anesthesia. Anesthesiology (1991) 74 581-605.

3 Maze M., Regan J.W. Role of signal transduction in anesthetic action. Alpha 2 adrenergic agonists. Ann. N. Y. Acad. Sci. (1991) 625 409-422.

4 Millan M.J. Descending control of pain. Prog. Neurobiol. (2002) 66 355-474.
5 Sonohata M., Furue H., Katafuchi T. et al. Actions of noradrenaline on substantia gelatinosa neurones in the rat spinal cord revealed by in vivo patch recording. J. Physiol. (2004) 555 515-526.

6 Vanhoutte P.M. Endothelial adrenoceptors. J. Cardiovasc. Pharmacol. (2001) 38 796-808.

7 Eisenach J.C. Muscarinic-mediated analgesia. Life Sci. (1999) 64 549-554.

8 de Moura R.S., Rios A.A., Santos E.J. et al. Role of the NO-cGMP pathway in the systemic antinociceptive effect of clonidine in rats and mice. Pharmacol. Biochem. Behav. (2004) 78 247-253.

9 Aronov S., Ben-Abraham R., Givati-Divshi D., Katz Y. Cerebroventricular injection of clonidine causes analgesia mediated by a nitrogen pathway. Drug Metabol. Drug Interact. (2005) 21 55-66.

10 Soares de Moura R.S., Leao M.C., Castro Resende A.C. et al. Actions of L-NAME and methylene blue on the hypotensive effects of clonidine and rilmenidine in the anesthetized rat. J. Cardiovasc. Pharmacol. (2000) 35 791-795.

11 Soares de Moura R., Rios A.A., de Oliveira L.F. et al. The effects of nitric oxide synthase inhibitors on the sedative effect of clonidine. Anesth. Analg. (2001) 93 1217-1221.

12 Khan Z.P., Ferguson C.N., Jones R.M. Alpha-2 and imidazoline receptor agonists. Their pharmacology and therapeutic role. Anaesthesia (1999) 54 146-165.

13 Han B.F., Zhang C., Reyes-Vazquez C., Qiao J.T., Dafny N. ATP-sensitive potassium channels and endogenous adenosine are involved in spinal antinociception produced by locus coeruleus stimulation. Int. J. Neurosci. (2004) 114 961-974.

14 Detweiler D.J., Eisenach J.C., Tong C., Jackson C. A cholinergic interaction in alpha 2 adrenoceptor-mediated antinociception in sheep. J. Pharmacol. Exp. Ther. (1993) $265536-542$

15 Hood D.D., Mallak K.A., Eisenach J.C., Tong C. Interaction between intrathecal neostigmine and epidural clonidine in human volunteers. Anesthesiology (1996) 85 315-325.

16 Pan H.L., Chen S.R., Eisenach J.C. Intrathecal clonidine alleviates allodynia in neuropathic rats: interaction with spinal muscarinic and nicotinic receptors. Anesthesiology (1999) 90 509-514.

17 Pinardi G., Sierralta F., Miranda H.F. Atropine reverses the antinociception of nonsteroidal anti-inflammatory drugs in the tail-flick test of mice. Pharmacol. Biochem. Behav. (2003) 74 603-608.

18 Yoon M.H., Yoo K.Y., Jeong C.Y. Synergistic effects between intrathecal clonidine and neostigmine in the formalin test. J. Korean Med. Sci. (2001) 16 498-504.

19 Pertovaara A. Noradrenergic pain modulation. Prog. Neurobiol. (2006) 80 53-83.

20 Lazaro-Ibanez G.G., Torres-Lopez J.E., Granados-Soto V. Participation of the nitric oxide-cyclic GMP-ATP-sensitive $\mathrm{K}(+)$ channel pathway in the antinociceptive action of ketorolac. Eur. J. Pharmacol. (2001) 426 39-44.

21 Ocana M., Baeyens J.M. Differential effects of $\mathrm{K}+$ channel blockers on antinociception induced by alpha 2-adrenoceptor, 
GABAB and kappa-opioid receptor agonists. Br. J. Pharmacol. (1993) 110 1049-1054.

22 Asano T., Dohi S., Iida H. Antinociceptive action of epidural $\mathrm{K}+(\mathrm{ATP})$ channel openers via interaction with morphine and an alpha(2)- adrenergic agonist in rats. Anesth. Analg. (2000) 90 1146-1151.

23 Collier H.O., Dinneen L.C., Johnson C.A., Schneider C. The abdominal constriction response and its suppression by analgesic drugs in the mouse. Br. J. Pharmacol. Chemother. (1968) 32 295-310.

24 Jones B.J., Roberts D.J. The quantiative measurement of motor in co-ordination in naive mice using an accelerating rotarod. J. Pharm. Pharmacol. (1968) 20 302-304.

25 Barros H.M., Tannhauser M.A., Tannhauser S.L., Tannhauser M. Enhanced detection of hyperactivity after drug withdrawal with a simple modification of the open-field apparatus. J. Pharmacol. Methods (1991) 26 269-275.

26 Takano Y., Yaksh T.L. Relative efficacy of spinal alpha-2 agonists, dexmedetomidine, clonidine and ST-91, determined in vivo by using N-ethoxycarbonyl-2-ethoxy-1,2dihydroquinoline, an irreversible antagonist. J. Pharmacol. Exp. Ther. (1991) $258438-446$.

27 Poree L.R., Guo T.Z., Kingery W.S., Maze M. The analgesic potency of dexmedetomidine is enhanced after nerve injury: a possible role for peripheral alpha2-adrenoceptors. Anesth. Analg. (1998) 87 941-948.

28 Guneli E., Karabay Yavasoglu N.U., Apaydin S., Uyar M. Analysis of the antinociceptive effect of systemic administration of tramadol and dexmedetomidine combination on rat models of acute and neuropathic pain. Pharmacol. Biochem. Behav. (2007) 88 9-17.

29 Mansikka H., Lahdesmaki J., Scheinin M., Pertovaara A. Alpha(2A) adrenoceptors contribute to feedback inhibition of capsaicin-induced hyperalgesia. Anesthesiology (2004) 101 185-190.

30 Millan M.J., Dekeyne A., Newman-Tancredi A. et al. S18616, a highly potent, spiroimidazoline agonist at alpha(2)adrenoceptors: I. Receptor profile, antinociceptive and hypothermic actions in comparison with dexmedetomidine and clonidine. J. Pharmacol. Exp. Ther. (2000) 295 1192-1205.

31 Buerkle H., Yaksh T.L. Pharmacological evidence for different alpha 2-adrenergic receptor sites mediating analgesia and sedation in the rat. Br. J. Anaesth. (1998) 81 $208-215$.

32 Ulger F., Bozkurt A., Bilge S.S. et al. The antinociceptive effects of intravenous dexmedetomidine in colorectal distension-induced visceral pain in rats: the role of opioid receptors. Anesth. Analg. (2009) 109 616-622.

33 Ruffolo R.R., . Jr, Nichols A.J., Stadel J.M., Hieble J.P. Pharmacologic and therapeutic applications of alpha 2-adrenoceptor subtypes. Annu. Rev. Pharmacol. Toxicol. (1993) 33 243-279.

34 Yamada K., Inagaki N. Neuroprotection by KATP channels. J. Mol. Cell. Cardiol. (2005) 38 945-949.
35 Miki T., Seino S. Roles of KATP channels as metabolic sensors in acute metabolic changes. J. Mol. Cell. Cardiol. (2005) 38 917-925.

36 Soundarapandian M.M., Zhong X., Peng L., Wu D., Lu Y. Role of K(ATP) channels in protection against neuronal excitatory insults. J. Neurochem. (2007) 103 1721-1729.

37 Ocana M., Cendan C.M., Cobos E.J., Entrena J.M., Baeyens J.M. Potassium channels and pain: present realities and future opportunities. Eur. J. Pharmacol. (2004) 500 203-219.

38 Nichols C.G. KATP channels as molecular sensors of cellular metabolism. Nature (2006) 440 470-476.

39 Xu Z., Chen S.R., Eisenach J., Pan H.L. Role of spinal muscarinic and nicotinic receptors in clonidine-induced nitric oxide release in a rat model of neuropathic pain. Brain Res. (2000) 861 390-398.

40 Duflo F., Conklin D., Li X., Eisenach J.C. Spinal adrenergic and cholinergic receptor interactions activated by clonidine in postincisional pain. Anesthesiology (2003) 98 1237-1242.

41 Ghelardini C., Galeotti N., Uslenghi C., Grazioli I., Bartolini A. Prochlorperazine induces central antinociception mediated by the muscarinic system. Pharmacol. Res. (2004) 50 351-358.

42 Dussor G.O., Helesic G., Hargreaves K.M., Flores C.M. Cholinergic modulation of nociceptive responses in vivo and neuropeptide release in vitro at the level of the primary sensory neuron. Pain (2004) 107 22-32.

43 Takizuka A., Minami K., Uezono Y. et al. Dexmedetomidine inhibits muscarinic type 3 receptors expressed in Xenopus oocytes and muscarine-induced intracellular $\mathrm{Ca} 2+$ elevation in cultured rat dorsal root ganglia cells. Naunyn Schmiedebergs Arch. Pharmacol. (2007) 375 293-301.

44 Calasans-Maia J.A., Zapata-Sudo G., Sudo R.T. Dexmedetomidine prolongs spinal anaesthesia induced by levobupivacaine $0.5 \%$ in guinea-pigs. J. Pharm. Pharmacol. (2005) 57 1415-1420.

45 Smith M.S., Schambra U.B., Wilson K.H. et al. Alpha 2Adrenergic receptors in human spinal cord: specific localized expression of mRNA encoding alpha 2-adrenergic receptor subtypes at four distinct levels. Brain Res. Mol. Brain Res. (1995) 34 109-117.

46 Knaus A.E., Muthig V., Schickinger S. et al. Alpha2adrenoceptor subtypes-unexpected functions for receptors and ligands derived from gene-targeted mouse models. Neurochem. Int. (2007) 51 277-281.

47 Sawamura S., Kingery W.S., Davies M.F. et al. Antinociceptive action of nitrous oxide is mediated by stimulation of noradrenergic neurons in the brainstem and activation of [alpha]2B adrenoceptors. J. Neurosci. (2000) 20 9242-9251.

48 Bjorklund M., Sirvio J., Sallinen J., Scheinin M., Kobilka B.K., Riekkinen P.Jr. Alpha2C-adrenoceptor overexpression disrupts execution of spatial and non-spatial search patterns. Neuroscience (1999) 88 1187-1198.

49 Scheinin M., Sallinen J., Haapalinna A. Evaluation of the alpha2C-adrenoceptor as a neuropsychiatric drug target studies in transgenic mouse models. Life Sci. (2001) 68 2277-2285. 
50 Sabbe M.B., Penning J.P., Ozaki G.T., Yaksh T.L. Spinal and systemic action of the alpha 2 receptor agonist dexmedetomidine in dogs. Antinociception and carbon dioxide response. Anesthesiology (1994) 80 1057-1072.

51 Otsuguro K., Yasutake S., Ohta T., Ito S. Effects of opioid receptor and alpha2-adrenoceptor agonists on slow ventral root potentials and on capsaicin and formalin tests in neonatal rats. Brain Res. Dev. Brain Res. (2005) 158 50-58.

52 Kendig J.J., Savola M.K., Woodley S.J., Maze M. Alpha 2adrenoceptors inhibit a nociceptive response in neonatal rat spinal cord. Eur. J. Pharmacol. (1991) 192 293-300.

53 Sullivan A.F., Kalso E.A., McQuay H.J., Dickenson A.H. The antinociceptive actions of dexmedetomidine on dorsal horn neuronal responses in the anaesthetized rat. Eur. J. Pharmacol. (1992) 215 127-133.

54 Bouaziz H., Tong C., Yoon Y., Hood D.D., Eisenach J.C. Intravenous opioids stimulate norepinephrine and acetylcholine release in spinal cord dorsal horn. Systematic studies in sheep and an observation in a human. Anesthesiology (1996) 84 143-154.

55 Chen B.S., Peng H., Wu S.N. Dexmedetomidine, an alpha2adrenergic agonist, inhibits neuronal delayed-rectifier potassium current and sodium current. Br. J. Anaesth. (2009) $103244-254$
56 Shirasaka T., Kannan H., Takasaki M. Activation of a G protein-coupled inwardly rectifying $\mathrm{K}+$ current and suppression of Ih contribute to dexmedetomidine-induced inhibition of rat hypothalamic paraventricular nucleus neurons. Anesthesiology (2007) 107 605-615.

57 Soini S.L., Duzic E., Lanier S.M., Akerman K.E. Dual modulation of calcium channel current via recombinant alpha2-adrenoceptors in pheochromocytoma (PC-12) cells. Pflugers Arch. (1998) 435 280-285.

58 Li B., Du T., Li H. et al. Signalling pathways for transactivation by dexmedetomidine of epidermal growth factor receptors in astrocytes and its paracrine effect on neurons. Br. J. Pharmacol. (2008) 154 191-203.

59 Peng L., Yu A.C., Fung K.Y., Prevot V., Hertz L. Alphaadrenergic stimulation of ERK phosphorylation in astrocytes is alpha(2)-specific and may be mediated by transactivation. Brain Res. (2003) 978 65-71.

60 MacLaren R. Immunosedation: a consideration for sepsis. Crit. Care (2009) 13191.

61 Dahmani S., Rouelle D., Gressens P., Mantz J. Characterization of the postconditioning effect of dexmedetomidine in mouse organotypic hippocampal slice cultures exposed to oxygen and glucose deprivation. Anesthesiology (2010) 112 373-378. 